\title{
Comparison of Oral Rifampicin with Observation Alone in Treatment of Acute Central Serous Chorioretinopathy
}

\author{
Anum Badar ${ }^{1}$, Sadaf Khan ${ }^{1}$, Sobia Usman Shah ${ }^{2}$, Muhammad Tahir ${ }^{3}$, Saman Babree ${ }^{1}$ \\ ${ }^{1}$ LRBT Eye Hospital Lahore \\ ${ }^{2}$ Combined Military Hospital Lahore, \\ ${ }^{3}$ Combined Military Hospital Rawalakot
}

\section{ABSTRACT}

Introduction: A randomized control trial to compare efficacy of oral rifampicin in terms of drying of macula and decrease macular thickness with observation alone in patients of acute central serous Chorioretinopathy done in Layton Rahmatulla Benevolent Trust (LRBT) Free Eye and Cancer Hospital, Lahore from January 2017 to June 2017

Methods: After getting approval from hospital Ethical committee 140 patients of CSR were included in the study. The demographic details were noted and patients were randomized by lottery methods in two groups (group A\& B). Group-A was observed for spontaneous resolution, routine treatment started if no improvement noted after 6 weeks of observation alone. Group B was given oral rifampicin 600mg per day for four weeks with liver function tests being done before commencement of treatment and after 2 weeks. Oral rifampicin was stopped if patient developed deranged liver function tests. Patients were followed up at 4 weeks for macular dryness and decrease macular thickness on optical coherence tomography(OCT). All the readings were carried out and noted by single person in order to minimize bias.

Results: A total of 140 patents, 70 in each group, were included in study with mean age $38.77 \pm 7.74$ in Group-A and 39.14 \pm 7.97 years in Group-B. regarding gender distribution $65.71 \%(n=46)$ in Group$A$ and $613.43 \%(n=43)$ in Group-B were male. Comparison of outcome of treatment of acute central serous chorioretinopathy with oral rifampicin vs observation showed that $18.57 \%(n=13)$ in Group$A$ and $41.43 \%(n=29)$ in Group-B had dry macula.

Conclusion: We concluded that there is a significant difference in drying of macula in acute central serous chorioretinopathy with Rifampicin versus observation alone.

KEYWORDS: Acute central serous Chorioretinopathy, oral rifampicin, drying of macula

Cite This Article: BADAR, Anum et al. Comparison of oral rifampicin with observation alone in treatment of acute central serous Chorioretinopathy. International Journal of Retina, [S.I.], v. 3, n. 1, feb. 2020. ISSN 26148536. Available at: https://www.ijretina.com/index.php/ijretina/article/view/103 Date accessed: 22 feb. 2020. doi: https://doi.org/10.35479/ijretina.2020.vol003.iss001.103.

*Correspondence to:

Anum Badar,

LRBT Eye Hospital Lahore,

Pakistan,

dranumbadar@gmail.com

\section{INTRODUCTION}

Central serous chorioretinopathy (CSCR) is defined as a serous detachment of the neurosensory retina over an area of leakage from the choriocapillaries through the retinal pigment epithelium (RPE). ${ }^{1}$ 
Incidence of visual loss in young adult men due to central serous chorioretinopathy is approximately $\mathrm{Z} 1 / 10,000^{2}$ which is 1.74 -fold higher than females. ${ }^{3}$ With a recurrence rate of $19.41 \%{ }^{4}$ Risk factors include exogenous steroid, type A personality, pregnancy, smoking, Cushing syndrome, H.Pylori infection and systemic lupus erythematosis. ${ }^{5}$

Central serous chorioretinopathy is thought to be caused by an impaired automatic response due to elevating circulating cortisol and epinephrine level which in turn affect the auto regulation of the choroidal circulation.

Specific psychological and personality profiles have been associated with CSCR but the exact link between anxiety-sensitive personalities and steroid biology has not been elucidated.

All this considered, it is clear that complex links between CSCR and corticosteroids are yet to be described. In this context, we have investigated and identified the mineralocorticoid receptor as a potential player in CSCR pathogenesis. This review will focus on recent findings that have furthered the epidemiology, the clinical understanding and the management of CSCR and will detail the possible role of the mineralocorticoid pathway in CSCR pathogenesis and treatment.

As central serious chorioretinopathy mainly effects young working male population, this novel treatment strategy would be tremendously beneficial in terms of early return to their activities and less socio-economic loss. Confirmation of efficacy of rifampicin opens the doors for this newer treatment modality.

\section{METHODS}

This Randomized control trial was done at Layton Rahmatulla Benevolent Trust (LRBT) Free Eye and Cancer Hospital, Lahore from January 2017 to June
2017. Ethical approval was taken from hospital Ethical committee and written consent was taken from all the participants. Sample size was calculated considering $80 \%$ power of test (1-beta). Sample was collected by non-probability consecutive sampling.

The patients with age ranging from 20 to 50 presenting within 3 weeks of symptoms onset were included as we were looking for role of rifampicin in acute CSR. All those patients with disease duration of more than 6 months, recurrent disease, having another ocular pathology and deranged liver function tests were excluded from study. Demographic information such as name, age, gender was noted at the time of recruitment. Preoperative assessment including visual acuity, slit lamp examination, FFA and macular thickness on OCT were carried out and patients were randomly assigned to group A or group B by using lottery methods. To avoid bias one experienced ophthalmologist who has done at least five hundred independent OCT performed all the OCT. Group A was observed (there was no ethical issues as observation alone is considered for spontaneous resolution up to 6 months before commencement of treatment). Group B was given oral rifampicin $600 \mathrm{mg}$ per day for four weeks. If there is no improvement after 6 weeks IN Group A, they were given the usual treatment. Liver function tests were repeated after two weeks in Group-Patient having deranged liver function tests were excluded from the study and oral rifampicin was stopped. Patients were followed up at 4 weeks to see decrease in macular thickness. All the readings were carried out and noted by single person in order to minimize bias. SPSS-21 was used for statistical analysis.

Quantitative variables like age and BCVA were presented as mean and standard deviations while qualitative variables like gender, efficacy in terms of macular dryness were presented as frequency and percentage. 
Chi square test was used to compare the qualitative outcomes i.e. efficacy (in terms of macular dryness) as per operational definition in both groups. Post stratification chi square test was applied. The $p$-value of $\leq 0.05$ was considered significant.

\section{RESULTS}

A total of 140 cases, (70 in each group), fulfilling the inclusion/exclusion criteria were enrolled in study. Age distribution of the patients shows that $41.43 \%(n=29)$ in Group-A and $40 \%(n=28)$ in Group$B$ were between 20-35 years of age whereas $58.57 \%(n=41)$ in Group-A and $60 \%(n=42)$ in Group$B$ were between $36-50$ years of age, mean \pm SD was calculated as $38.77 \pm 7.74$ in Group-A and $39.14 \pm 7.97$ years in Group-B.

Table 1. Age distribution $(\mathbf{n}=\mathbf{1 4 0})$

\begin{tabular}{ccccc}
\hline \multirow{2}{*}{$\begin{array}{c}\text { Age } \\
\text { (in years) }\end{array}$} & \multicolumn{2}{c}{$\begin{array}{c}\text { Group-A } \\
(n=70)\end{array}$} & \multicolumn{2}{c}{$\begin{array}{c}\text { Group-B } \\
(n=70)\end{array}$} \\
\cline { 2 - 5 } & $\begin{array}{c}\text { No. of } \\
\text { patients }\end{array}$ & $\%$ & $\begin{array}{c}\text { No. of } \\
\text { patients }\end{array}$ & $\%$ \\
\cline { 2 - 5 } $20-35$ & 29 & 41.43 & 28 & 40 \\
\hline $36-50$ & 41 & 58.57 & 42 & 60 \\
\hline Total & 70 & 100 & 70 & 100 \\
\hline & & & & \\
\hline
\end{tabular}

Gender distribution shows that $65.71 \%(n=46)$ in Group-A and $613.43 \%(n=43)$ in Group-B were male while $34.29 \%(n=24)$ in Group-A and $38.57 \%(n=27)$ in Group-B were females.Mean BCVA was calculated as $0.17 \pm 0.10$ in Group-A and $0.15 \pm 0.12$ in Group-B
Table 2. Mean bcva $(\mathbf{n}=\mathbf{1 4 0})$

\begin{tabular}{ccccc}
\hline BCVA & \multicolumn{2}{c}{$\begin{array}{c}\text { Group-A } \\
(n=70)\end{array}$} & \multicolumn{2}{c}{$\begin{array}{c}\text { Group-B } \\
(n=70)\end{array}$} \\
\cline { 2 - 5 } Mean & SD & Mean & SD \\
\hline 0.17 & 0.10 & 0.15 & 0.12
\end{tabular}

Comparison of efficacy of oral rifampicin in terms of drying of macula with observation alone in patients of acute central serous chorioretinopathy shows that $18.57 \%(n=13)$ in Group-A and $41.43 \%(n=29)$ in Group-B had efficacy whereas $81.43 \%(n=57)$ in Group-A and $58.57 \%(n=41)$ in Group-B had no findings of efficacy, $p$ value was 0.03 showing a significant difference. Effect modifiers like age, gender, visual acuity (pretreatment BCVA), duration of disease was controlled through stratification. Post-stratification chi square test was applied. $P$ value of $\leq 0.05$ was considered significant.

Table 3. Comparison of efficacy of oral rifampicin in terms of drying of macula with observation alone in patients of acute central serous chorioretinopathy ( $n=140)$

\begin{tabular}{ccccc}
\hline \multirow{2}{*}{ Efficacy } & \multicolumn{2}{c}{$\begin{array}{c}\text { Group-A } \\
(\mathbf{n = 7 0 )}\end{array}$} & \multicolumn{2}{c}{$\begin{array}{c}\text { Group-B } \\
(\mathbf{n = 7 0 )}\end{array}$} \\
\cline { 2 - 5 } & $\begin{array}{c}\text { No. of } \\
\text { patients }\end{array}$ & $\%$ & $\begin{array}{c}\text { No. of } \\
\text { patients }\end{array}$ & $\%$ \\
Yes & 13 & 18.57 & 29 & 41.43 \\
No & 57 & 81.43 & 41 & 58.57 \\
\hline Total & 70 & 100 & 70 & 100 \\
\hline
\end{tabular}


Table 4. Stratification for efficacy with regards to age ( $n=140)$

AGE: $\mathbf{2 0 - 3 5}$ years

\begin{tabular}{|c|c|c|c|}
\hline \multirow[t]{2}{*}{ Group } & \multicolumn{2}{|c|}{ Efficacy } & \multirow{2}{*}{$\begin{array}{c}\text { P value } \\
0.03\end{array}$} \\
\hline & Yes & No & \\
\hline A & 6 & 23 & \\
\hline B & 13 & 15 & \\
\hline
\end{tabular}

AGE: $36-50$ years

\begin{tabular}{|c|c|c|c|}
\hline \multirow[t]{2}{*}{ Group } & \multicolumn{2}{|c|}{ Efficacy } & \multirow{2}{*}{$\begin{array}{l}\text { P value } \\
0.03\end{array}$} \\
\hline & Yes & No & \\
\hline A & 7 & 34 & \\
\hline B & 16 & 26 & \\
\hline
\end{tabular}

Table 5. Stratification for efficacy with regards to gender $(n=140)$

MALE

Group

Efficacy P value

\begin{tabular}{cccc}
\cline { 2 - 3 } & Yes & No & 0.01 \\
A & 10 & 36 & \\
\hline B & 20 & 23 \\
\hline
\end{tabular}

FEMALE

\begin{tabular}{|c|c|c|c|}
\hline \multirow[t]{2}{*}{ Group } & \multicolumn{2}{|c|}{ Efficacy } & \multirow{2}{*}{$\begin{array}{c}\text { P value } \\
0.08\end{array}$} \\
\hline & Yes & No & \\
\hline A & 3 & 21 & \\
\hline B & 9 & 18 & \\
\hline
\end{tabular}

\section{DISCUSSION}

Poor visual outcome and frequent exacerbations are the features of central serous retinopathy (CSR). Very few therapies exist for CSR, and the existing therapies are often ineffective. Some investigators believe that initial choroidal vascular compromise subsequently leads to secondary dysfunction of the overlying RPE They proposed that choroidal hyper permeability causes serous detachments of the RPE, which can induce a rip or decompensation of the RPE. Alterations in choroidal circulation may also cause choroidal ischemia.

An alternative theory suggests that CSC results from dysfunction of the RPE. This occurs following an undefined insult. It results in either a few impaired RPE cells or even a single RPE cell, which causes a reverse in fluid movement in a chorioretinal direction. This, in turn, leads to leakage of fluid in the subretinal space and finally to the development of a neurosensory retinal detachment.

The relation between CSCR and corticoids is probably one of the most intriguing aspects of the disease. Glucocorticoids efficiently reduce macular edema of many origins, even when associated with subretinal fluid, ${ }^{15}$ but glucocorticoids can aggravate subretinal fluid accumulation in CSCR patients.. But high-dose intraocular injection of glucocorticoids, routinely administered for the treatment of macular edema, has not been associated with increased incidence of CSCR. Such discrepancies reflect the still non-elucidated complexity of steroids regulation on ocular physiopathology.

Specific psychological and personality profiles have been associated with CSCR but the exact link between anxiety-sensitive personalities and steroid biology has not been elucidated and the full ocular and systemic steroid hormonal profile of CSCR 
patients has been only partially explored. More determinants should be now considered in light of recent discoveries linking stress, corticosteroids, epigenetic modifications and cardiovascular risk factors.

Life style modification is advised to reduce the circulating cortisol levels with stopping of exogenous glucocorticoids. Patients are observed for the period of three months for spontaneous resolution. Focal laser, photodynamic therapy and intravitreal bevacizumab was previously considered mainstay of treatment. Newer advances in treatment of central serous chorioretinopathy include systemic anti glucocorticoids e.g. mifepristone, ketoconazole, rifampicin, eplerenone etc. ${ }^{6-7}$

Rifampicin is an anti-tuberculous medication which is thought to facilitate catabolism of endogenous steroids. It causes a proliferation of the smooth endoplasmic reticulum and an increase in the cytochrome P-450 content in the liver, thus affecting the metabolism and bioavailability of endogenous corticosteroids, consequently aiding in resolution of CSCR and improving its symptomatology. ${ }^{75,76}$ However, care is to be taken as hepatotoxicity can develop as a side effect while being treated for CSCR. ${ }^{77}$

A study published in Iranian journal of ophthalmology evaluated therapeutic effects of rifampicin in acute central serous chorioretinopathy. Results showed significant drying of macula in treatment group $45.5 \%$ than control group $24.9 \%$.

As central serious chorioretinopathy mainly effects young working male population, this novel treatment strategy would be tremendously beneficial in terms of early return to their activities and less socio-economic loss. Confirmation of efficacy of rifampicin opens the doors for this newer treatment modality.

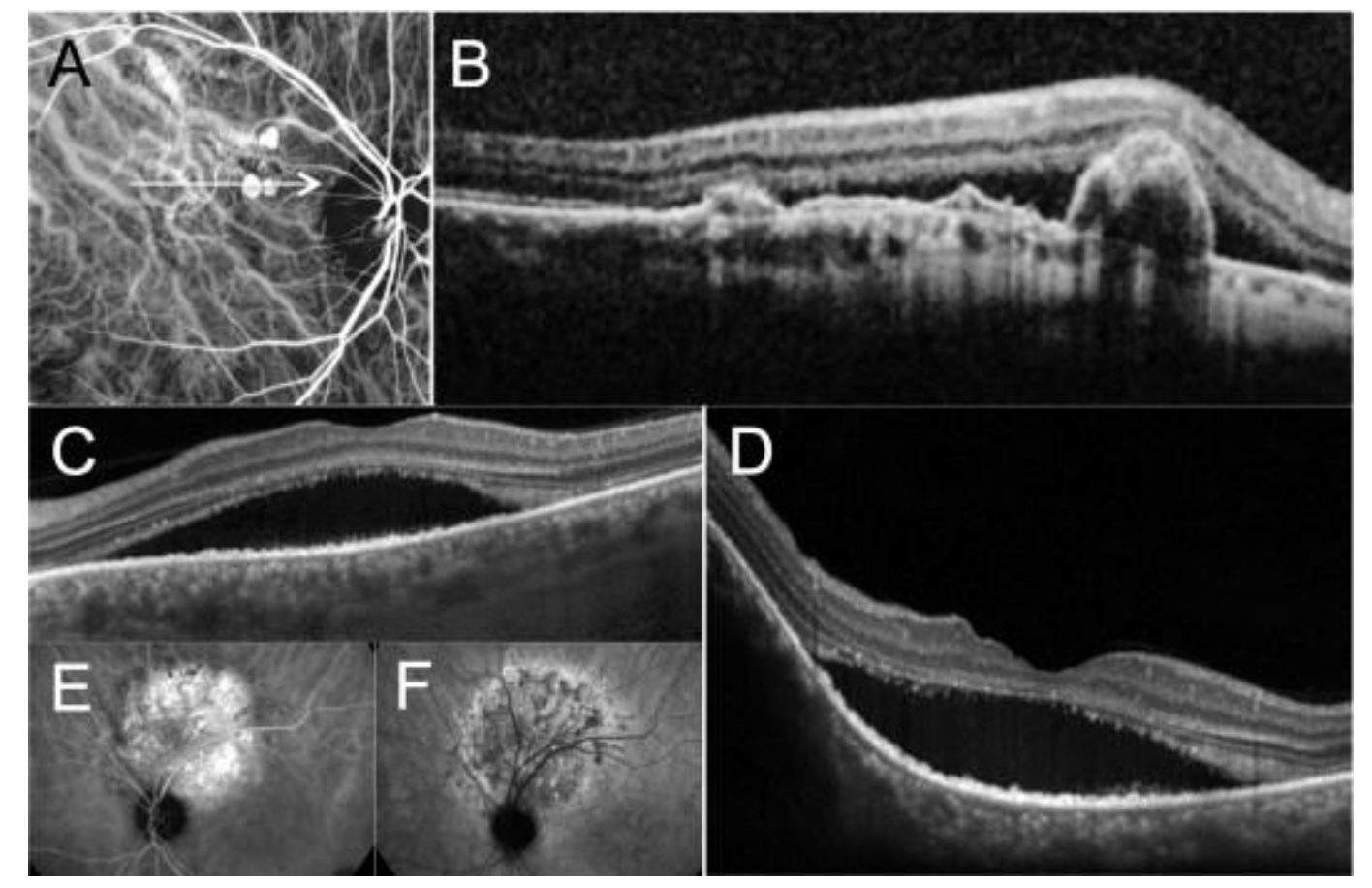

Figure 1. Acute central serous chorioretinopathy with asymptomatic involvement of the contralateral eye 


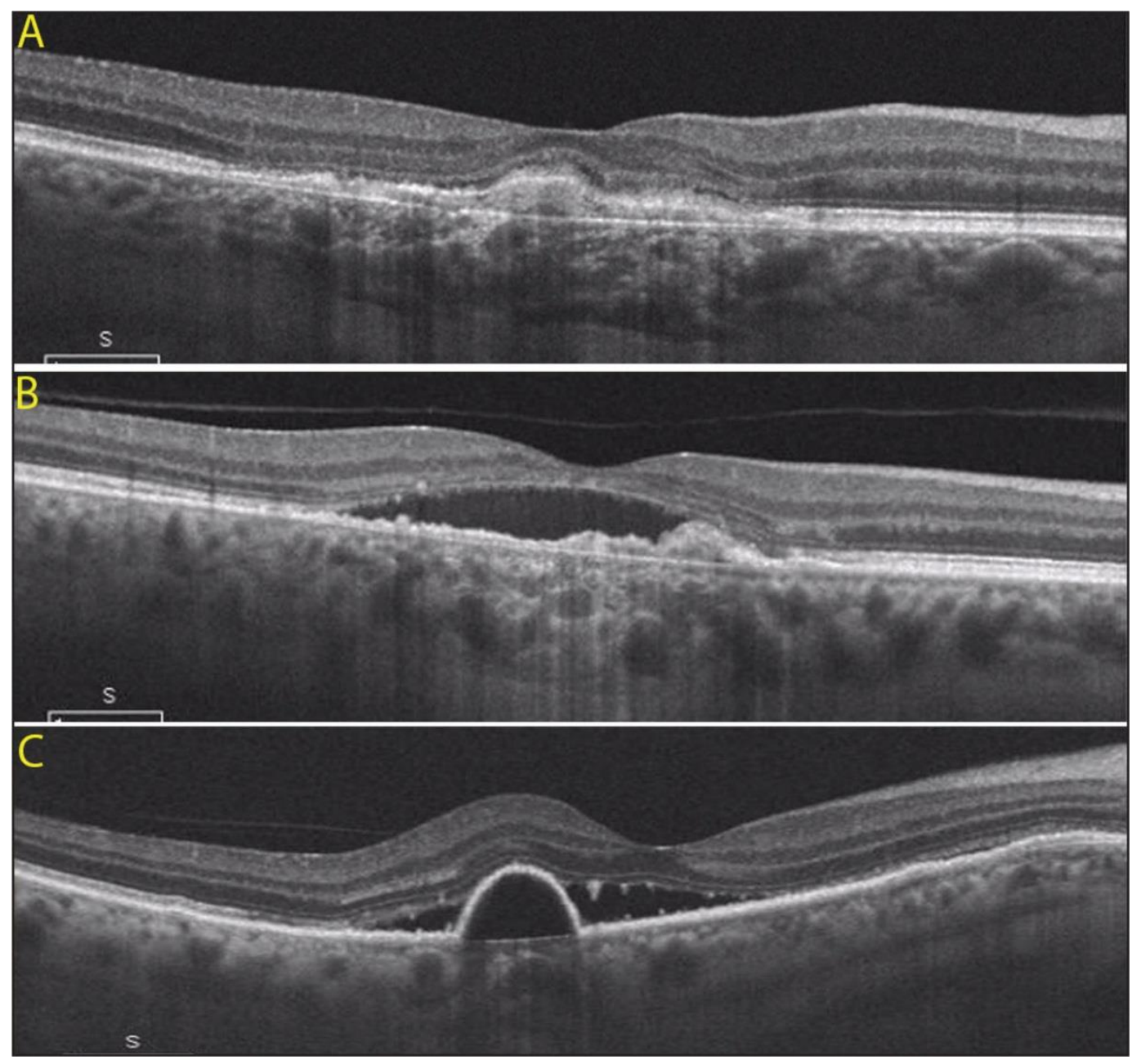

Figure 2. Acute central serous chorioretinopathy in two cases, with increased and normal choroidal thickness

In our study, out of 140 cases (70 in each group), $41.43 \%(n=29)$ in Group-A and $40 \%(n=28)$ in Group$B$ were between 20-35 years of age whereas $58.57 \%(n=41)$ in Group-A and 60\% $(n=42)$ in Group$B$ were between $36-50$ years of age, mean \pm sd was calculated as $38.77 \pm 7.74$ in Group-A and 39.14 \pm 7.97 years in Group-B, 65.71\%(n=46) in Group-A and $613.43 \%(n=43)$ in Group-B were male while $34.29 \%(n=24)$ in Group-A and $38.57 \%(n=27)$ in Group-B were females. Comparison of efficacy of oral rifampicin in terms of drying of macula with observation alone in patients of acute central serous chorioretinopathy shows that $18.57 \%(n=13)$ in Group-A and $41.43 \%(n=29)$ in Group-B had efficacy whereas $81.43 \%(n=57)$ in Group-A and
$58.57 \%(n=41)$ in Group-B had no findings of efficacy, $p$ value was 0.03 showing a significant difference.

We compared our results with a study published in Iranian journal of ophthalmology evaluated therapeutic effects of rifampicin in acute central serous chorioretinopathy. Results showed significant drying of macula in treatment group than control group. Macula was dried in $45.5 \%$ of treatment group and $24.9 \%$ control group. ${ }^{8}$ Our findings are in agreement with the above study.

Zac B. Ravage and others ${ }^{80}$ evaluated the efficacy of oral rifampin for the treatment of CSC. They recorded that the follow-up was 8 weeks for two patients and 12 weeks for three patients. 
One patient self-discontinued rifampin after 3 weeks of treatment. One patient developed choroidal neovascularization after 2 months, treated with IVA and excluded from further analysis. Reported side effects of treatment include headache in 1 patient and nausea in 1 patient. Mean change in central macular thickness (CMT) from baseline OCT was -99 (SD \pm 167$) \mu \mathrm{m}$ at week 1, $-102(\mathrm{SD} \pm 215) \mu \mathrm{m}$ at week 8 and $-93(S D \pm 91) \mu \mathrm{m}$ at week 12. Change in CMT for each patient was $-440,-217,-64,1$ and $118 \mu \mathrm{m} .3$ patients gained 0 lines of vision, 2 patients gained $\geq 3$ lines of vision. They concluded that Rifampin may be of potential benefit to patients with CSC. Acute cases appear to respond most favorably. Sub-retinal fluid may decrease with treatment, while sub-RPE fluid often persists. These early findings suggest a novel method for the treatment of chronic CSC and warrants further study.

The findings of our study confirms the efficacy of rifampicin and opens the doors for this newer treatment modality which would speed and recovery with high response rate,

\section{CONCLUSION}

We concluded that there is a significant difference in efficacy in terms of drying of macula in acute central serous chorioretinopathy with Rifampicin versus observation alone.

\section{REFERENCES}

1. Fruschelli $M$, Denaro $R$, Esposti $G$, Frezzotti $P$, Torchia R, Esposti PL. New diagnostic and therapeutic strategies in acute and chronic central serous chorioretinopathy. Acta Ophthalmologica 2013;91(252):0.

2. Liew G, Franzco GQ, Franzco MG, Franzco SF. Central serous chorioretinopathy: a review of epidemiology and pathophysiology. Clinical \& Experimental Ophthalmology 2012;41:201-4.
3. Tsai D, Chen S, Huang C, Chou P, chung C, Huang P. Epidemiology of Idiopathic central serous chorioretinopathy in Taiwan 2001-2006: a population-based study; 2013;8:e66858.

4. Elias A, Goplakrishnan M, Nair D, Bhatt S, Gudapati R, Annantharaman G. A 10 year study of Central Serous Chorioretinopathy: Recurrence rate and factors affecting recurrence. WJORV 2011;1:69-74.

5. Daruich A. Central serous chorioretinopathy: recent findings and new physiopathology hypothesis.[accessed on June 21, 2015]

6. Howard F, Michael D, Seenu M. Current concepts in managing central serous chorioretinopathy. OSLI 2014;45:9-13.

7. Pitcher JD, CSCR: Diagnosis and treatment. [accessed on June 21, 2015]

8. Sabouri MR, Kazemnezhad E. Evaluation of therapeutic effect of Rifampicin for acute central serous chorioretinopathy. Iranian Journal of Ophthalmology 2014;26:102-7.

9. Lehmann $M$, Wolff $B$, Vasseur $V$, Martinet $V$, Manasseh N, Sahel JA, Mauget-Faÿsse $M$. Retinal and choroidal changes observed with "En face" enhanced-depth imaging OCT in central serous chorioretinopathy $\mathrm{Br}$. J. Ophthalmol., 1997;97:1181-6.

10. Kitzmann AS, Pulido JS, Diehl NN, Hodge DO, Burke JP. The incidence of central serous chorioretinopathy in Olmsted County, Minnesota, 1980-2002. Ophthalmology. 2008;115(1):169-73.

11. Liew G, Quin G, Gillies M, Fraser-Bell S. Central serous chorioretinopathy: a review of epidemiology and pathophysiology. Clin Experiment Ophthalmol. 2012 Jul 12.

12. Tewari HK, Gadia R, Kumar D, Venkatesh P, Garg SP. Sympathetic-parasympathetic activity and reactivity in central serous chorioretinopathy: a case-control study. Invest Ophthalmol Vis Sci. 2006;47(8):3474-8. 
13. Carvalho-Recchia CA, Yannuzzi LA, Negrao S. Corticosteroids and central serous chorioretinopathy. Ophthalmology. 2002;109(10):1834-7.

14. Cotticelli L, Borrelli M, D'Alessio AC. Central serous chorioretinopathy and Helicobacter pylori. Eur J Ophthalmol. 2006;16(2):274-8.

15. Prunte C, Flammer J. Choroidal capillary and venous congestion in central serous chorioretinopathy. Am J Ophthalmol 1996;11:26-34.

16. Spitznas M. Pathogenesis of central serous retinopathy: a new working hypothesis. Graefe's Arch Clin Exp Ophthalmol 1986;224:321-24.

17. Yannuzzi LA. Type-A behaviour and central serous chorioretinopathy. Retina 1987;7:111-30.

18. Mansuetta CC, Mason JO, Swanner J, Feist RM, White MF, Thomley ML, McGwin G, Emond TL. An association between central serous chorioretinopathy and gastroesophageal reflux disease Am. J. Ophthalmol., 2004;137:10961100

19. Wu ZH, Lai RY, Yip YW, et al. Improvement in multifocal electroretinography after half-dose verteporfin photodynamic therapy for central serous chorioretinopathy: a randomized placebo-controlled trial. Retina. 2011;31: 13781386.

20. Steinle NC, Gupta N, Yuan A, Singh RP. Oral rifampin utilisation for the treatment of chronic multifocal central serous retinopathy. $\mathrm{Br}$ J Ophthalmol. 2012;96(1):10-13.

21. Nelson J, Saggau DD, Nielsen JS. Rifampin induced hepatotoxicity during treatment for chronic central serous chorioretinopathy. Retin Cases Br Rep. 2014;8(1):70-72.

22. Ravage ZB, Packo KH. Rifampin for Treatment of Central Serous Chorioretinopathy. Investigative Ophthalmology \& Visual Science 2011;52:2137. 